\title{
Agroecologia urbana e a demanda pela racionalização das políticas municipais
}

\section{Cristiane Rocha Silva}

Professora Mestre do curso

Tecnólogo em Agroecologia.

Universidade Federal do Paraná.

Bruno Alexandre da Silveira

Graduado Tecnólogo em Agroecologia.

Universidade Federal do Paraná.
Universidad y salud /

Intervenciones

\section{Resumo}

O projeto de extensão Agroecologia urbana coordenado pela Universidade Federal do Paraná, procura articular práticas urbanas saudáveis com foco na consciência ambiental junto à população do município de Matinhos, Paraná, região sul do Brasil. A metodologia do grupo permitiu que suas ações fossem enriquecidas e modificadas com o diálogo. Dessa forma, a intenção inicial do projeto, que consistia em quintais produtivos para melhoria da alimentação, ampliou-se para atender outras necessidades relacionadas com a captação da água da chuva, a compostagem, redes de troca. A experiência com o projeto evidenciou a necessidade de articulação com as políticas municipais para a gestão do espaço urbano, estimulando a racionalização dos recursos mediante políticas tributárias ou viabilização de espaços coletivos. Nesse sentido, nos arriscamos a pontuar algumas reflexões e ações políticas que viabilizariam uma ação coletiva ampliada, com o fomento a saúde pública, a partir das mudanças das práticas urbanas de convivência.

Palavras-chave

- agroecologia urbana

- agricultura urbana

- compostagem

- meio ambiente

\section{Contexto e ações do projeto de extensão "Agroecologia urbana"}

A agricultura urbana tem se aproximado das políticas públicas, sendo trata em âmbito do governo federal, estadual, municipal e tratados internacionais (Arruda, 2006) e discutida em diferentes âmbitos relacionando a políticas de desenvolvimento social e segurança alimentar.

A partir das discussões no âmbito do IV Congresso Latinoamericano de Agroecologia (SOCLA, 2013) e das leituras do documento da FAO (2013), Quon (1999), Pessôa (2005) e LeeSmith (2009), podemos dizer que a agricultura urbana consiste em um grupo de ações de produção ecológicas e comunitárias de plantas alimentares, não alimentares e animais integrados com espaços urbanos reduzidos com peculiaridades de manejo e organização próprios.

Soonya Quon (1999), ao discorrer sobre as diferentes definições da agricultura urbana, ressalta a importância que a definição transcorra sobre cinco aspectos, são eles: localização, atividades, posse da terra e legalidade, estágio e escala. Dessa forma é importante conceituar a agricultura urbana de forma a ser próxima da realidade de cada região ou país, salientar quais os espaços se considera, sejam eles, espaços públicos, terrenos baldios, quintais, telhados, terraços, varandas, vasos e jardineiras, sítios ao entorno da cidade (location). A especificação dos tipos de atividade envolve a produção de plantas alimentícias ou não alimentícias (ornamental, fertilizante, cosmética, medicinal, florestal, artesanal, etc.), criação de animais, produção ou coleta (activities). Ainda o conceito deve abarcar a legalidade da posse da terra, pública ou privada e a forma de uso coletivo ou individual (landownership, legality), se inclui como uso coletivo do espaço público os hortos comunitários, as redes da agricultura urbana, as iniciativas do governo municipal e regional de promoção de cidades sustentáveis. Como estágio entende-se a especificação dos momentos da cadeia produtiva abarcados, seja a semeadura, plantio, transformação, comercialização e distribuição (stage). Nesse aspecto poderia-se acrescentar os espaços coletivos de compostagem, preparação de mudas, formação, troca e partilha de alimentos.

O quinto fator, que segundo Soonya Quon (1999) deve estar presente na definição da agricultura urbana é a escala de produção, relacionado a uma área mínima e máxima para as atividades (scale). A autora analisa 22 definições de agricultura urbana elaboradas a partir das realidades próprias e suas peculiaridades em diferentes partes no mundo. Tais definições nos fundamentam para arriscarmos em uma definição adequada às práticas do projeto de extensão do qual serão relatadas as reflexões sobre o tema. Portando, elaboramos a seguinte definição, a qual fundamenta a utilização do termo Agroecologia urbana no presente estudo na visão dos autores. Agroecologia urbana consiste em um grupo de ações de trocas e produção ecológica de vegetais e animais em quintais domésticos, com extensão de até uma quadra dentro da cidade ou caracterizados como agricultura familiar na área peri urbana. Com ações voltadas à melhoria da qualidade de vida das famílias envolvidas direta e indiretamente. Trocas solidárias dos resultados do trabalho e conhecimento. Organização pautada em uma ação coletiva na produção de insumos, geração de energia e aprendizagem colaborativa em espaços públicos de organização 


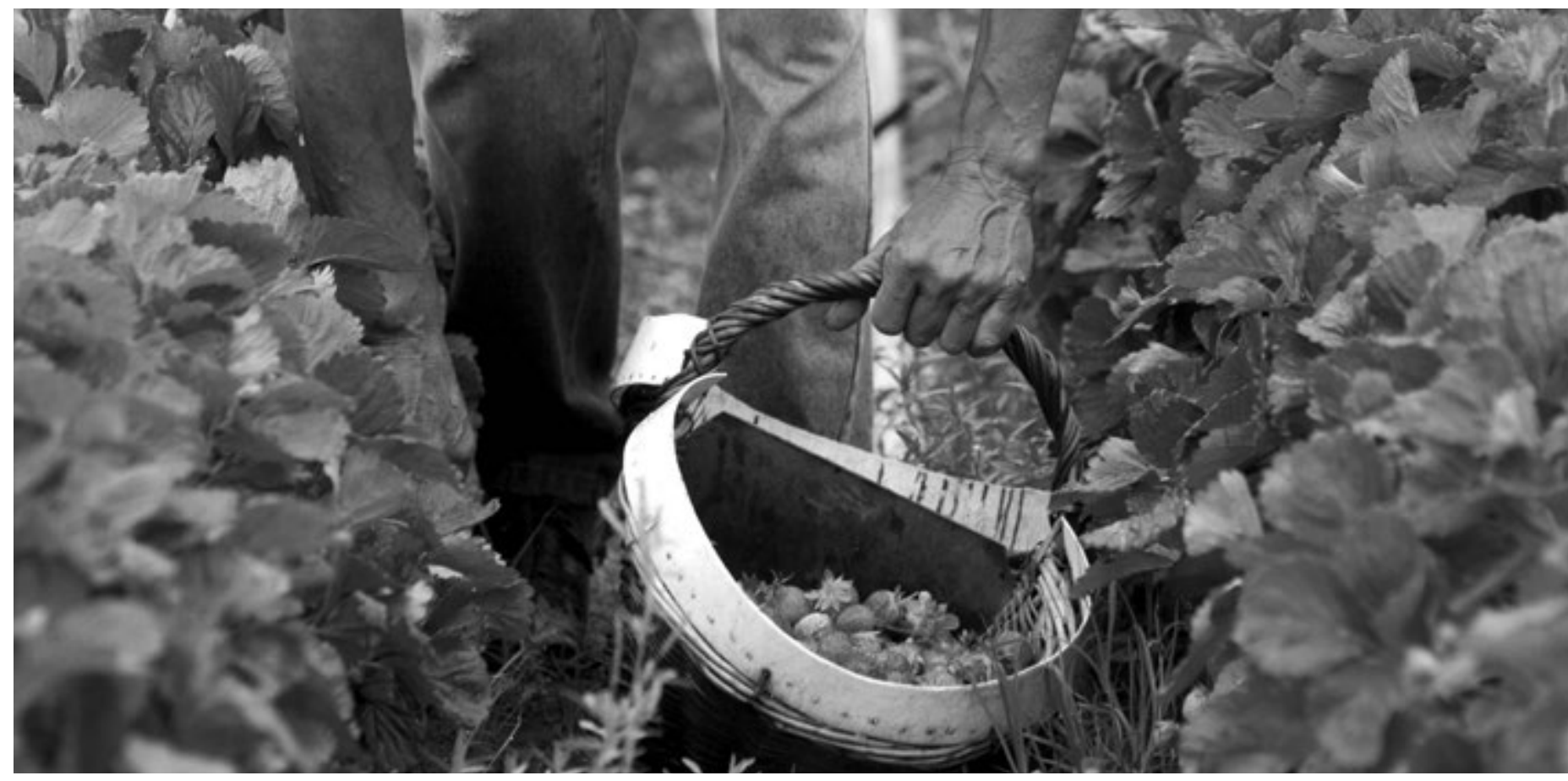

formal ou informal. Fundamentalmente apoiada por políticas públicas, saber local tradicional e projetos acadêmicos, legitimados pela sociedade civil.

A definição enfoca como atividades principais: 1) a produção ecológica; 2) a troca solidária; 3) a ação coletiva nas atividades de apoio (compostagem, energia, insumos, formação) em espaços públicos (associações, prefeitura, parques); 4) a integração e apoio do poder público, sociedade civil, saber local tradicional e universidades.

No contexto da agricultura urbana, não poderíamos desconsiderar que a produção está associada ao consumo político e as estratégias de controle do paladar e hábitos alimentares dos cidadãos ancoradas por interesses econômicos de concentração de renda.

Assim, observa-se o consumidor cada vez mais distante da forma de produção e processamento dos alimentos. Também cada vez mais o cidadão está restrito ao papel de consumidor. Na mesma proporção, os alimentos se transformam. Cada vez menos alimento e mais conservantes e aromatizantes são disponibilizados no mercado. Menor tempo dedicado no preparo, no consumo, na confraternização do alimento.

Por outro lado, muitas famílias despendem grande parte do seu orçamento em alimentação industrializada e pouco nutritiva, mesmo existindo espaços de terra ociosos em seus lotes, quintais, vizinhança. Assim, surgem inúmeras iniciativas que buscam melhorar a qualidade dos alimentos consumidos e incentivar a produção de alimento nas cidades, sejam nos quintais, nas áreas públicas ou nas escolas, evidenciando a necessidade de redescobrir as plantas regionais, adaptadas ao solo e clima, bem como o equilíbrio na preservação do ambiente.

O projeto agroecologia urbana é parte de tais iniciativas e procura promover o trabalho coletivo e a troca de experiências em mutirões nos quintais, estimulando a produção, a otimização dos recursos naturais, o aprendizado permanente e o fortalecimento afetivo e espiritual dos grupos.

No presente estudo, descreveremos a nossa reflexão sobre as possibilidades de ação do poder público sobre três linhas de ação do projeto agroecologia urbana.

1) Compostagem da matéria orgânica: o reaproveitamento dos resíduos da cozinha, podas e aparas do quintal manejados na composteira, nutre o solo para produção e nutre e melhora a estrutura do solo aumentando a produção de alimentos, simultaneamente reduz significativamente o material destinado aos lixões, contribuindo para o meio ambiente, a horta e a economia dos serviços públicos. $\mathrm{O}$ incentivo à construção ou processos de compostagem nos quintais, a discussão do tema da destinação do resíduo e a busca de informações e preparação para a construção de composteiras foram ações realizadas pelos membros do projeto. 2) Captação de água da chuva: embora abundante o litoral do Paraná, a água da chuva é muito pouco aproveitada, e em períodos da alta temporada do turismo os bairros da periferia sofrem restrição no uso da água tratada. A instalação de cisternas possibilita um reservatório para diversos usos não potáveis nas residências. Essa é uma demanda dos participantes do projeto, 
em planejamento, entre os membros do projeto para execução em setembro de 2014.

3) Produção e consumo de plantas regionais / tradicionais: o enfoque nas plantas tradicionais consiste em redescobrir as plantas de potencial nutritivo e potencial, com maior facilidade de cultivo na região. O levantamento das plantas dos quintais, a identificação de plantas de uso alimentício e medicinal, a troca de mudas e receitas estão presentes nas reuniões semanais do projeto.

As ações compõem um trabalho de mudança ao longo prazo, para o qual, a consolidação de uma rede de agroecologia urbana busca agregar pessoas que tenham um pensamento próximo e busquem ações concretas para melhoria da qualidade de vida das famílias no município de Matinhos. O papel das políticas municipais e a ação governamental tem se destacado como um ator social importante para estimular e coordenar a adoção das práticas saudáveis e ambientalmente responsáveis na convivência urbana.

\section{Metodologia}

A metodologia pauta-se na participação dos atores no planejamento, execução e avaliação das ações e objetivos. Os grupos de roda de conversa periódicos contribuem na aproximação e formação dos atores sociais, sejam docentes, discentes ou moradores do município de Matinhos. As ações são planejadas de acordo com as necessidades dos moradores e possibilidade de aprendizado dos acadêmicos. A temática foco demanda pesquisas, análises, planejamento da operacionalização, busca de recursos, síntese do conhecimento no formato de oficinas e os resultados são avaliados pelo grupo e contribuem na reflexão das novas atividades. As ações ocorreram em formato de curso no ano de 2013 e adquiriu o formato de projeto de extensão no ano de 2014, com dois professores coordenadores, cinco estudantes bolsistas; uma escola de educação infantil; e três moradoras do bairro Mangue-Seco. A abordagem metodológica fundamentase nos princípios da agroecologia e no conceito de resiliência sócio ecológico (Nicholls, 2013). Ou seja, estimula o equilíbrio do homem e da natureza a partir do respeito e adaptação com as peculiaridades ambientais e culturais do local.

\section{A racionalização das práticas de convivência urbana e a coerência das políticas municipais}

A convivência no espaço urbano, em particular, nas cidades com menos de 40 mil habitantes, tem demonstrado pecularidades, na gestão das práticas cotidianas. Se de um lado não existe a produção em volume de resíduos orgânicos e sólidos como nos centros urbanos, também inexistem atores que se responsabilizem pela coordenação e gestão de tais resíduos de forma racional. Nesse sentido, as ações de responsabilidade ambiental estão relacionadas à consciência dos cidadãos em adotar mudanças nas práticas de convivência. A seguir evidenciamos uma série de irracionalidades recorrentes nas observações do cotidiano urbano e levantadas pelas ações do projeto de extensão Agroecologia urbana e a descrição de experiências realizadas em diferentes municípios evidenciando que as irracionalidades poder ser amenizadas, se adotada uma racionalidade ambiental que incentive a participação e autonomia das comunidades e o incentivo na estruturação e manutenção de projetos em torno da agroecologia urbana de forma interdisciplinar e integrativa dos setores da gestão pública.

1) Compostagem da matéria orgânica: o descarte de vegetais, cascas, podas, plantas nos sacos de lixo. Parece-nos irracional pensar nos nutrientes que poderiam ser aproveitados nas hortas, por técnicas de compostagem e vermicompostagem. Ao contrário são tratados como lixo não aproveitável, aumentam o volume do lixo recolhido pelo serviço público por representar em média metade do peso do resíduo total, e sobrecarregam e poluem os espaços de destinação. Por outro, lado, possuir uma composteira doméstica, tem seus contratempos, relacionado ao tempo de manejo, a atração de roedores, a presença de odores e insetos, o espaço necessário. A ação municipal, nesse sentido, adquire um papel central, por ser responsável pela contratação dos serviços de coleta; controle do imposto predial urbano e dos estímulos do desconto progressivo. A orientação e distribuição de composteiras domésticas, por condomínio e o incentivo pelo desconto progressivo de tributos seriam uma contribuição para atrair maior número de participantes e fundamentar uma gestão efetiva de resíduos orgânicos da área urbana. Rosa (2012) traz uma importante reflexão sobre a prevenção da saúde a partir da determinação social, evidenciando como o contexto social e econômico se relaciona com as condições de saúde do grupo social. Na sua análise das percepções dos membros do grupo, a pesquisadora encontra como categorias para explicar o fenômeno social: a promoção da saúde; o início do evento; a revolução, processo, cultura, emancipação/autonomia e benefício individual; a institucionalização e o poder público; o intelectual orgânico, educação e interdisciplinaridade. A autora se baseia em Rosen (1979 apud Rosa, 2012) para evidenciar a doença como um fenômeno social que deve ser estudado no seu contexto biosocial. Com essa abordagem, relata a experiência denominada "A Revolução dos Baldinhos" na comunidade Chico Mendes, município de Florianópolis, Santa Catarina, Brasil. Trata-se de um processo de compostagem com recolhimento em baldes distribuídos às famílias e processados em um espaço coletivo com adequado condicionamento do período de 2006 com continuidade até o período de pesquisa de Rosa (2012). Segundo a análise da autora, foi importante para a continuidade e resultados do projeto, principalmente a participação efetiva da comunidade. A parceria com o poder público é vista ao mesmo tempo como uma 
necessidade a ser assumida e gerida para fins de saúde pública, por outro lado, relatada com receio pelos membros do grupo, que aspiram uma autonomia conseguida pelo grupo nas decisões do projeto. É manifestado o anseio de que a economia gerada pela redução na coleta e transporte dos resíduos fosse repassada ao grupo. As parcerias são citadas no histórico do projeto, como bolsa aos envolvidos, espaço cedido para composteira, orientação do agente de saúde e técnico para acondicionamento e diminuição dos ratos e moscas, na relação horizontal com os moradores e incentivo a apresentação do projeto nos espaços de eventos. O principal fator que levou a composteira tornar-se coletiva, na experiência com os baldinhos, foi a infestação de ratos e moscas, no período de 2006 a 2008, com a propagação das composteiras domésticas vinculadas a agricultura urbana na comunidade. Essa experiência evidencia como a comunidade organizada contribui na promoção da saúde, e ainda, como a organização da composteira coletiva, é uma alternativa viável da gestão de resíduos, da qual o poder público deve assumir a iniciativa de estímulo e estruturação, no entanto, não em detrimento da participação ativa e autônoma dos membros da comunidade.

2) Captação de água da chuva: falta de agua para uso doméstico em um território de clima úmido. Não parece nada sensato, no município de Matinhos, localizado no litoral do Paraná, entre o oceano Atlântico e a Serra do Mar, os moradores da periferia sofrerem contenção de água no período de temporada (dezembro e janeiro) quando a população de veraneio sobrecarrega o consumo de água. Uma ação pública de incentivo à captação de água da chuva para população de risco, bem como, a articulação com a empresa de saneamento e esgoto, para amenizar a restrição e conceder as devidas orientações para o correto uso e captação da água são fundamentais para a racionalização do recurso. Segundo Silva y Domingos (2007) a captação da água da chuva não é algo novo, e serve para usos não potáveis, reduzindo em até $50 \%$ o uso de água de uma residência. Para ser utilizada como água potável necessita de uma filtragem mais fina para remoção de elementos químicos, e, a retirada dos patogênicos. A água da chuva consiste em uma fonte de água disponível e abundante, bem como evita o desperdício de água tratada que apresenta um maior custo. As autoras ressaltam que a adoção da captação de água é difundida em diferentes países e que a qualidade da água captada está relacionada com fatores ambientais, carecendo de análise específica da água de acordo com sua destinação. Em seu estudo, Silva y Domingos (2007) apontam à necessidade da regulamentação dos recursos hídricos pelo poder público e descrevem leis adotadas em diferentes municípios brasileiros. As autoras apontam que,

"a preocupação com o uso racional da água deve partir principalmente do poder público que deve assumir sua função garantindo a todos os cidadãos esse direito"

(Silva y Domingos, 2007:71).
Entre as experiências mencionadas, são citadas, no Rio de Janeiro, a Lei estadual 4.393 de 16 setembro de 2004 que dispõe sobre a obrigatoriedade das empresas projetistas e de construção civil a prover imóveis residenciais e comerciais de dispositiva para captação de água da chuva; e a Lei estadual 4.248 de 16 de dezembro de 2003 institui o programa de captação de águas pluviais no âmbito do estado do Rio de Janeiro.

No Rio Grande do Sul, o Programa estadual de captação e manejo da água da chuva (PECMAC) foi lançado em 2005, como foco em amenizar o efeito das estiagens e consiste na construção de cisternas e microbarragens.

No estado do Paraná, no município de Curitiba, a Lei 10.785 de setembro de 2003, obriga a todos os novos condomínios residenciais a incorporarem no projeto de construção, a captação, o armazenamento e a utilização da água da chuva para múltiplos usos em substituição à água clorada. A lei torna obrigatório o uso de vasos sanitários, torneiras e chuveiros que economizem água, e ainda, obriga a instalação de hidrômetros individuais nas novas edificações, evitando que o rateio do condomínio no uso da água estimule o desperdício.

As autoras concluem que

"na maioria dos países desenvolvidos, dá-se incentivo à captação de águas pluviais com o objetivo de conservação de água no meio urbano e como medidas não estruturais de drenagem. Já nos países subdesenvolvidos, os programas ocorrem principalmente em regiões secas, restando basicamente a construção de cisternas como fonte de abastecimento" (Silva y Domingos, 2007:74).

Dessa forma evidenciam-se os desafios e as potencialidades que existem no processo de captação de água da chuva no ambiente urbano, ainda precários e subutilizados no território brasileiro. 3) Produção e consumo de plantas regionais/tradicionais: desprezar hortaliças que nascem vigorosas e espontâneas na região para adquirir hortaliças estrangeiras produzidas e vendidas em escala à base de insumos. Não é desprezível que o paladar das populações é fruto de uma construção e troca étnica dos movimentos migratórios no último século. Mas convenhamos que, a solidificação dos hábitos alimentares favoreceu muitos interesses econômicos, de comercialização de insumos e produtos com facilidade de produção e distribuição em escala, reduzindo muito a variedade de vegetais consumidos e padronizando independentes das condições locais, os itens consumidos. O processo de industrialização e urbanização a partir da década de 1950 acirrou uma padronização da alimentação reduzindo a participação de itens regionais nas dietas das famílias brasileiras, segundo Bleil (1998). As hortaliças e frutas consumidas pelas populações até meados do século XX são hoje nobres desconhecidas dos consumidores. A política governamental de aquisição de alimentos, bem como o planejamento nutricional das intituições escolares, hospitalares e outros contribuem na oferta por 
parte dos produtores familiares das plantas alimentícias tradicionais. Uma ação que repercute na manutenção da cultura gastronômica do território e nas formas de fomento da produção familiar. Por outro lado, o incentivo à agricultura urbana e à produção de alimentos no município deve estar associada à disponibilidade e facilidade de crescimento das plantas regionais bem como à adaptação das sementes, ao solo e clima e à racionalização dos tipos de solo e sua utilização. A coordenação de espaços produtivos em torno do Parque Saint-Hilarie Lang, coordenando as áreas de ocupação e protegendo os limites do Parque, por exemplo, é algo a ser inserido no planejamento das áreas para agricultura urbana. Considerase uma irracionalidade desviar os cursos dos rios e aterrar para construção ás áreas de solo fértil na região. Um adequado plano de manejo com incentivo à agricultura urbana auxiliaria na preservação do Parque e a melhoria da qualidade de vida dos moradores do entorno. De acordo com o mapa geológico do estado do Paraná, as características do solo ao entorno do Parque, são considerados férteis e facilitariam a produção de alimentos, em uma região litorânea, de solo predominantemente arenoso (Mineropar, 2006).

O texto de Dupim e Brum em 1973 (traduzido por Sayona, 1982) denuncia as contradições presentes nas mudanças alimentares ocorridas em países africanos em desenvolvimento e aponta o desafio de complementação dos processos tradicionais e modernos e a necessidade de que o processo alimentar não deixe as populações alheias ao seu meio natural. Nesse mesmo período, no Brasil, era crescente o movimento da Revolução Verde, a modernização agrícola como substituição aos atrasados modos de produção colonial. Ao analisar a evolução da alimentação nos países em desenvolvimento Dupim e Brun em 1973 (Sayona, 1982), denunciam o papel dos meios de comunicação na mudança de hábitos alimentares. Seja reduzindo o interesse nos produtos e processos tradicionais ou fortalecendo o prestígio de produtos importados dos países desenvolvidos. Ao mesmo tempo que os fatores ligados a urbanização, industrialização, redução do tempo dedicado ao preparo do alimento e ampliação das relações comerciais no meio rural influenciaram na mudança de hábitos alimentares nos países em desenvolvimento.

"Muchas madres de familia están convencidas de que solo las frutas importadas contienen vitaminas y son 'buenas para la salud' de sus hijos. La idea de vitamina, que les era ajena anteriormente, está asociada a la idea de fruta extranjera; los médicos y enfermeros prescriben una 'cucharada de jugo de naranja' porque esto les ha sido enseñado durante sus estudios en Europa, ignorando el contenido de vitamina $\mathrm{C}$ de los frutos locales" (Sayona, 1982:36).

Tais mudanças tiveram, segundo os autores, seus benefícios entre os grupos que influenciaram, entretanto, os resultados geraram uma fragilidade econômica dos países em desenvolvimento no valor agregado das trocas do que se produz e o que se consome. Gerando consequentemente grande produção e cada vez menos prioridade de terras férteis e tempo de trabalho aos produtos da alimentação em relação aos produtos de troca, mais rentáveis. Mesmo a doação de alimentos aos países em desenvolvimento é vista como perigosa aos hábitos alimentares dos países em desenvolvimento. Segundo os autores, salvo casos de emergência, são considerados "regalos envenenados", pois criam na população o hábito de consumir produtos que o país não produz e não pode produzir. A síntese da vulnerabilidade econômica dos países em desenvolvimento nas suas escolhas de produzir para o comércio é elucidada pelo seguinte trecho:

"La dependencia de los términos de intercambio del mercado mundial de los productos principales de la economía de plantación, hace que se disminuyan en intensidad los cultivos intercalados, afectando la producción de los alimentos básicos, ante lo cual aparece 1á alternativa de la importación de alimentos y la creación de complejos agro industriales nacionales o extranjeros; los productores de alimentos básicos quedan de esta forma dependiendo de las condiciones del desarrollo de la economía capitalista" (Sayona, 1982:24).

Em contraposição à fome e à dificuldade de produção de alimentos massificados mundialmente, há uma série de plantas de valor alimentício constatado, amplamente consumidas no Brasil anteriormente ao processo de intensa industrialização da alimentação. Essas plantas são tratadas como plantas daninhas e pragas nos jardins e plantações, cada vez mais desconhecidas na sua nomenclatura e valor nutricional, com reduzido ou nenhum potencial de mercado, embora abundantes e de fácil cultivo. São exemplos na região costeira do Brasil, estado do Paraná, as plantas Taioba (Xanthosoma sagittifolium), Falsa Serralha (Emilia fosbergii), Ora-pronobis (Pareskia aculeata) e Pepino-do-mato (Melothria fluminensis), plantas de potencial alimentar e medicinal do bioma Mata Atlântica, tratadas como plantas daninhas ou pragas (Lorenzi, 2008). O movimento de escolhas dos itens da alimentação consumo e produção estão relacionados a interesses econômicos, portanto, a reflexão sobre tais processos necessita de uma interferência no fluxo atual, no sentido, de resgatar e valorizar as plantas regionais e a utilização das mesmas na alimentação escolar, na orientação dos técnicos e agentes de saúde nas comunidades, bem como no incentivo à produção da agricultura urbana, com a reprodução de sementes e divulgação das receitas de pratos que incluem itens da biodiversidade local.

\section{Considerações finais}

As demandas apontadas pelo grupo têm em comum, refletirem a mudança nas práticas de convivência urbana no intuito de amenizar o impacto ambiental das relações de consumo das nossas 
comunidades. Apesar de pautar-se na consciência ambiental e reflexões da existência dos grupos humanos nas cidades ressalta a necessidade da gestão coletiva para melhoria da qualidade de vida dos moradores. A ação municipal na gestão dos resíduos, na coordenação da captação de água, na participação nos programas de aquisição de alimentos governamentais, no apoio aos grupos de rede de trocas e feiras e fundamentalmente na estruturação de espaços urbanos coletivos para controle dos impactos ambientais nas regiões urbanas prescinde de uma visão racional e sistêmica. Com foco na responsabilidade dos resíduos gerados e nas formas de gestão coletiva e alternativas de consumo em relação às trocas econômicas monetárias e individuais com apelo visual da publicidade do consumismo. A observação e vivência com as demandas do projeto de extensão evidenciaram as irracionalidades consolidadas no comportamento do cidadão e no estímulo das políticas públicas a um consumismo e resolução individual dos problemas ambientais. Ou seja, uma racionalidade econômica, em oposição a uma racionalidade da responsabilidade ambiental e convivência urbana responsável e

\section{Referências}

Arruda, J. (2006). "Agricultura urbana e peri urbana em Campinas/SP: análise doprograma de hortas comunitárias como subsídio para políticas públicas" (dissertação de mestrado publicada) UNICAMP Campinas, SP. Disponível em: http://dominiopublico.mec.gov.br/download/ea000499.pdf (acesso em 23 de julho de 2014).

Bleil, S. a I. (1998). "O Padrão Alimentar Ocidental: considerações sobre a mudança de hábitos no Brasil". En Cadernos de Debate, Vol. VI, Disponível em: http://www.uftm.edu.br/upload/ensino/AVIdiscednu090804095840.pdf (acesso em 20 de fevereiro de 2013).

FAO - Food and Agriculture Organization of the United Nations (2001). "Urban and peri - urban agriculture: A briefing guide for the successful implementation of Urban and Peri - urban Agriculture in Developing Countries and Countries of Transition". Rome, Italy. Disponível em http://www.fao.org/docs/eims/upload/215253/ briefing_guide.pdf (acesso em 28 de novembro de 2013).

Lee-Smith D. (2009). "Carrot City: Disgning for urban agriculture" En: Urban Agriculture magazine RUAF number 22. Disponível em: http://www.ruaf.org/ sites/default/files/UAM22\%20Carrot\%20City\%2043 - 44.pdf (acesso em 10 de fevereiro de 2014).

Lorenzi, H. (2008). Plantas medicinais no Brasil: nativas e exóticas. 2.ed. Nova Odessa, SP: Instituto Plantarum.

MINEROPAR (2006). "Mapa Geológico do estado do Paraná”. Disponível em: http://www.mineropar.pr.gov.br/arquivos/File/2_Geral/Geologia/PDF_Mapa_ Geo_650000/Mapa_Geologico_PR_650000_2006.pdf (acesso em 24 de julho de 2014).

Nicholls, C. I. y Altieri, M. A. (2012). "Estratégias agroecológicas para incrementar la resiliencia”. En: Leisa Revista de Agroecología, V2, 24. Disponível em: http:// www.leisa - al.org/web/revistas/volumen - 28 - numero - 2/482 - estrategias - agroecologicas - para - incrementar - la - resiliencia.html (acesso em 15 de outubro de 2013). saudável. Repensar as práticas cotidianas do ambiente urbano e a racionalidade das políticas públicas torna-se imprescindível para uma melhoria da qualidade de vida das populações urbanas.

Como conclusão desse estudo, evidencia-se como grande irracionalidade o foco nas iniciativas individuais para resolução dos impactos ambientais. Por mais bem intencionadas que sejam as pessoas, o controle dos impactos ambientais no município não pode ser resolvido individualmente. Faz parte da urbanidade, a convivência social, a necessidade de acordo com a vizinhança, os espaços públicos de gestão coletiva. Dessa forma, talvez como pilar principal, o incentivo, disponibilização e coordenação de espaços físicos destinados a composteiras coletivas, hortas comunitárias, lavanderias com reutilização da água, centros apropriados para clubes de trocas e feiras. Tais espaços embora sejam de necessidades das unidades domésticas necessitam de uma gestão coletiva, e para não serem elitizados aos grupos que puderam organizar-se financeiramente, necessita de aportes da gestão pública para sua implantação e manutenção.

Pessôa, C. C. (2005). "Agricultura urbana e pobreza: um estudo no município de Santa Maria - RS" (dissertação de mestrado publicada). Programa de pós graduação em extensão rural Universidade Federal de Santa Maria, RS. Disponível em: http://cascavel.ufsm.br/tede/tde_busca/arquivo.php?codArquivo=1643 (acesso em 23 de julho de 2014).

Quon, S. (1999). "Planning for Urban Agriculture: A Review of Tools and Strategies for Urban Planners". Urban agriculture definitions. IDRC, Canada. Disponível em: http://www.international - food - safety.com/pdf/Cities\%20Feeding\%20 - \%20 Planning\%20For\%20Urban\%20Agriculture\%20 - \%20A\%20Review\%20Of\%20 Tools\%20And\%20Strategies\%20For\%20Urban\%20Planners.pdf (acesso em 28 de novembro de 2013).

Rosa, G. Ramos da (2012). "A prevenção como princípio, a promoção como meio e a revolução como fim: uma história sobre a revolução dos baldinhos" Dissertação (mestrado) - Universidade Federal de Santa Catarina, Centro de Ciências da Saúde, Programa de Pós - Graduação em Saúde Coletiva, Florianópolis. Disponível em https://repositorio.ufsc.br/handle/123456789/100580 (acesso em 31 de julho de 2014).

Sayona, B. (1982). "Evolucion de la alimentacion em los países em vias de desarrollo" (traduzido de) Cahiers de: - lutritiün et de Clentifíque. Vol. VIII. 1973. "Evolutíon de l'alímen. tatiún dans les pays en voie de devoloppment". H. Dupll1 y T.8run. Disponivel em revistas.javeriana.edu.co/index.php/desarrolloRural/article/ download/4274/3243 (acesso em 31 de maio de 2013).

Silva, V. N da; Domingos, P. (jan-jun 2007). "Captação e Manejo de água da chuva" Em Saúde \& Ambiente em Revista, Duque de Caxias, Rio de janeiro, Brasil, Vol. 2, № 1, pp. 68-76. Disponível em: http://publicacoes.unigranrio.edu.br/index. php/sare/article/viewFile/264/255 (acesso em 31 de julho de 2014). SOCLA - Sociedade Latinoamericana de Agroecologia (2013). Anais dos IV Congresso Latinoamericano de Agroecologia. Lima. 